\title{
Opinion \\ Desertification of marine coastal ecosystems in ap: impact on fisherfolk
}

Volume 5 Issue I - 2017

\section{Opinion}

Shrinkage in fertile land based agriculture sector opened a new hope of growth in sun rising fishing sector in the recently bifurcated state of Andhra Pradesh in India. Once, marine coasts are the abundant resources and magnificent gift of Nature but now turned as dry sand deserts, salt deserts and hunger hotspots. Desertification of marine coastal ecosystems is the best indication of the multiple pressures and excessive bureaucratization of fish governance in the state leading the fishery sector as vain. According to Rothschild $\mathrm{BJ}^{1}$ "Fishery Management becomes an implicit coin flipping exercise, wasting both the resource and the capital invested in fishing operations, a tragedy in a day and age where we all need to live under sustainability imperative". The marine fisheries in India are regulated both by the central and state governments, there is no overall improvement in the quality of human life of marine fishermen. Moreover, most of the government schemes are confined to the papers only because of government's tendency to initiate schemes without setting aside enough funds to successfully implement them, thereby almost willing them to failure. Henceforth, investing in large scale industrial fishing, building bigger boats, poaching of fish, bottom trawling and giving subsidies for pursuing deep sea fishing would be a waste of resources as the fish hauls in the state of Andhra Pradesh coastal communities have dropped off alarmingly in recent years. The land and water systems in A.P. are suffering with both anthropogenic as well as natural disasters. The pollution and poverty pangs are the outcome governance in the state of A.P.

Year by year downfall of marine fisheries are recorded due to the indiscriminate and unstructured fishing practices at coast and marine ecosystem. The poverty pang prevails in the fishing communities of Andhra coast. Since from its inception time immemorial, marine fishers are being among the poorest communities and occupied lowest status in the social ladder in India. Poverty elimination and resolving the bitter conflicts among the fisher communities is a global challenge. There is an urgent need to safeguard the marine fisher and conserve the dwindling coastal and marine ecosystem on priority basis. Illegal fishing and 'fishing down' by Pauly et al. ${ }^{2}$ were both identified as being major threats to the fisheries; they will continue to operate at an unsustainably. The main reason for the problem of poverty in fishing communities is fishing governance in the state and as a whole in India. The fishing sub-sector is an informally operated by illiterate fishermen communities, is ruled by elite and literate people of the society. Withholding the poverty and pollution in static mode for longer period might cause either self-extinction or territorial and occupational change. However, there is no comprehensive marine fisheries legislation in India. ${ }^{3}$ Fisheries within the $12 \mathrm{~nm}$ territorial zone fall under the jurisdiction of the States, which are responsible for managing and collecting official fisheries statistics under the Marine Fishing Regulation Act (MFRA). ${ }^{3,4}$

Social disruption typically occurs in coastal areas where there is intense competition over scarce natural resources as a consequence

\author{
Jaya Kumar Jacob $M$ \\ Environmental Studies, Humanities \& Basic Sciences \\ Department, India
}

Correspondence: Jaya Kumar Jacob M,Associate Professor Environmental Studies, Humanities \& Basic Sciences Department, Chirala Engineering College, India, Tel 9849461379, Email mjaykumarjacob@gmail.com

Received: January 12, 2017 | Published: January 20, 2017

of rapid development of an unplanned and unregulated nature. The Fisheries management and policy compliance an international comparison by Pitcher et al. ${ }^{5}$ shows that the fisheries management performance score of India is $2 / 6$ with low level at policy design, Policy implementation and overall policy performance, stand at $8^{\text {th }}$ in world ranking for landings. Fiscal processes that direct funds from the centre to coastal states tend to support in subsidies and welfare schemes for fishers rather than reward good fisheries management performance.

The sad state of agriculture in A.P. was not only inspired human sacrifice but also trying to grab the fisheries into a ruined field. All the poverty alleviation programmes of both the GOs \& NGOs are either nominal or temporary or non-functional due to the short sightedness, growing disparities among the fishing communities based on the gears that were used, ultimately leading to the depletion of fish.

Discrimination in budget allocation to the vulnerable as well as disaster proven regions of the country is one of the major problems in India. A.P. state is one of the major disaster proven regions in the country. Poverty is also an unavoidable and undesirable qualification of Indian masses, directly or indirectly leading to many other problems, side effects. The lived experience of marine fishermen communities in Andhra Pradesh reveals that the politically driven welfare policies of Governments are working towards the country's economic growth rather than to safeguard the fishermen communities to alleviate poverty and pollution pangs. India is dreaming and rushing towards the double digit economic growth rate by ignoring ecological security as well as sustainability and stability of the country.

Discriminating pressure on the natural resources leads to economic and social disruptions and conflicts. Already diminishing resources leading to the collapse of the fisheries are depriving millions of people of their primary resources. Many fish populations around the world are subject to challenges from both sustainable and unsustainable fishing, pollution, habitat degradation, and "global change" As it 
was the case of Andhra Pradesh fisheries. Globalization of seafood markets has made fisheries increasingly competitive. Real prices for fish products have shown increased only moderately. ${ }^{6}$ While costs of key inputs like labour have risen. Due to the bureaucratic exercises, some of the fishing communities will disappear. The communities and the firms offering the best prices over time are most likely to thrive. Improved fisheries management provides fishers with more opportunities to maximize harvest value by accounting for valuable attributes of the harvest such as species, harvest timing, fish size, product form, and landing location, Harvest values can also vary by vessel and gear type. ${ }^{7}$ Bureaucratization of every field in the country is the major threat and cause of desertification. Bureaucracies have no soul, no memory, and no conscience. If there is a single stumbling block on the road to the future, it is the bureaucracy as we know it.

\section{Acknowledgments}

None.

\section{Conflicts of interest}

None.

\section{References}

1. Rothschild BJ. On the birth and death of ideas in marine science. ICES Journal of Marine Science. 2015;72(5):1237-1244.

2. Pauly D, Christensen V, Dalsgaard J, et al. Fishing down marine food webs. Science. 1998;279(5352):860-863.

3. Rajagopalan R. In Sanders JS, Gréboval D \& Hjort A (Eds.), Marine protected areas: country case studies on policy, governance and institutional issues. FAO Fisheries and Aquaculture Technical Paper 556/1, Rome. 2011;pp.33-49.

4. Bhathal B. Historical reconstruction of Indian marine fisheries catches, 1950-2000, as a basis for testing the 'Marine Trophic Index'. Fisheries Centre Research Reports. 2005;13(4):122.

5. ftp://ftp.fisheries.ubc.ca / CodeConduct.

6. Tveteras S, Asche F, Bellemare MF, et al. Fish is food-the FAO's fish price index. PLoS One. 2012;7(5):e36731.

7. Asche F, Chen Y, and Smith MD et al. Economic incentives to target species and fish size: Prices and fine-scale product attributes in Norwegian fisheries. ICES Journal of Marine Science. 2014;72(3):733740

8. Edward T. Hall, Beyond Culture, Anchor Publishing. 1977;pp.219. 